To use or not to use?

\title{
An empirical study of pre-trip public transport information for business and leisure trips and comparison with car travel
}

\author{
Sendy Farag* \\ Glenn Lyons
}

* Corresponding author

Centre for Transport \& Society (CTS)

University of the West of England (UWE)

Frenchay Campus, Coldharbour Lane

Bristol BS16 1QY

United Kingdom

Tel $0044(0) 1173281178$

Fax $0044(0) 1173283002$

E-mail:

sendyfarag@hotmail.com

glenn.lyons@uwe.ac.uk 


\begin{abstract}
This quantitative study provides more insight into the relative strength of various factors affecting the use and non-use of pre-trip public transport (PT) information for business and leisure trips. It also illuminates comparing car with public transport and its consequences for mode choice. The factors affecting PT information use most strongly are travel behaviour and sociodemographics, but travel attitudes, information factors, and social surrounding also play a role. Public transport use and PT information use are closely connected, with travel behaviour having a stronger impact on information use than vice versa. Information service providers are recommended to market PT information simultaneously with public transport use.
\end{abstract}

Key words: Travel information, Journey planning, Public transport, Travel behaviour, Structural Equation Modelling (SEM)

\title{
Acknowledgements
}

This paper is part of a 3-year study within the FUTURES initiative (Future Urban Technologies: Undertaking Research to Enhance Sustainability) which is funded in the UK by the EPSRC (Engineering and Physical Sciences Research Council). The authors wish to thank Dr. Tim Schwanen (University of Oxford, Transport Studies Unit) for his helpful comments.

\section{Abbreviated article title}

Pre-trip public transport information use and non-use 


\section{Introduction}

Transport policy in many countries has placed increasing importance on influencing people's mode choice. Accordingly, there has been a continued growth and investment in the provision of public transport (PT) information services. Yet usage of PT information services can seem disappointingly low and awareness of them does not necessarily lead to use (GfK NOP, 2007; Peirce and Lappin, 2004). Thus, what affects the use of PT information has become a key consideration.

There has been a lot of attention in academic literature regarding the use of ATIS (Advanced Traveller Information Services) and their effect on car drivers' propensity to change their route or mode for, mostly, familiar trips (Chorus et al., 2006a; Lyons et al., 2007). Relatively less attention has been paid to pre-trip PT information use and journey planning (Lyons et al., 2007). Most PT information is likely to be collected pre-trip, when decisions about travel mode are made (Grotenhuis et al., 2007). Examples of pre-trip PT information use are: online comparing train with car for a business trip, ringing a PT information service provider to ask the journey time and price of a particular trip by coach, and asking a neighbour the departure time of a local bus. Although some studies have investigated the requirements for PT information via stated needs (Chorus et al., 2007; Grotenhuis et al., 2007; Molin and Timmermans, 2006) only a few empirical studies exist that deal with revealed needs and use of PT information (AEA, 2007; Cain, 2007; Ipsos MORI, 2006). Moreover, these latter studies are descriptive rather than explanatory.

The goal of this paper is to provide insight into the relative strength of various factors affecting the use and non-use of pre-trip PT information for: 1) long distance (over 50 miles) business and leisure trips, and 2) the comparison of car with public transport for unfamiliar and any long distance trips, and its 
consequences for mode choice. These trip types were chosen because previous research has shown that people acquire PT information mostly for unfamiliar trips, arrival time-sensitive trips (such as business trips), longer distance trips, and leisure trips (AEA, 2007; Farag and Lyons, 2008; GfK NOP, 2007; Ipsos MORI, 2006). All trips concern travel within the UK. Unfamiliar trips could be both short or long distance, but overall the types of trips researched are primarily long distance trips. This implies that the type of PT information studied is more likely to pertain to rail and coach, rather than local bus or tram.

Specific attention has been paid to the direction of influence between public transport use and PT information use, since this could have important consequences for policy makers and transport professionals. Overall, expectations regarding the potential of PT information use to bring about a modal shift from car to public transport are moderate (Chorus et al., 2006b; Ipsos MORI, 2006; Lyons et al., 2007; Van der Horst, 2006), in spite of earlier policy expectation being greater. We also researched what affects information factors (e.g., the dislike to look up train information) and social surrounding (e.g., receiving a recommendation from people you know to use a particular PT information service).

Data were collected via a postal survey that was sent to a random sample of 10,000 households in the city of Bristol and the Greater Manchester area, UK. The response rate was $13 \%(n=1327)$. Structural Equation Modelling (SEM) was employed to investigate assumed interdependencies among the factors studied and to gain more insight into the direction of influence between public transport use and PT information use. In SEM, a variable can be both an outcome variable and an explanatory variable at the same time. For example, we analysed how information factors and social surrounding affect PT information use, but also what influences these factors. SEM also enables the relationships 
between variables to be decomposed into total, direct, and indirect effects (Jöreskog and Sörbom, 2001).

In the next section a hypothetical model based on earlier research is presented which has guided the analysis. This is followed by the methodology in section 3 . The results are given in section 4 and their implications are discussed in section 5 .

\section{Hypothetical model}

Using insights from attitude theory (Ajzen, 1991; Perugini and Conner, 2000) and previous empirical research done by others (AEA, 2007; Cain, 2007; Goulias et al., 2004; Ipsos MORI, 2006; Van der Horst, 2006; Verplanken et al., 1997), we have conducted both qualitative and quantitative research into pre-trip PT information use (Farag and Lyons, 2008, 2010). Below, we describe which factors are important for PT information use and what relationships we expect to occur between them. Figure 1 represents this hypothetical model. We studied the effect of the following factors on pre-trip PT information use:

1. Travel behaviour (e.g., frequency of car use and public transport use),

2. Travel attitudes (e.g., towards car and public transport),

3. Information factors (e.g., ease of obtaining and understanding, and trusting PT information via Internet, telephone, and timetables),

4. Social surrounding (e.g., knowing many people who use public transport, receiving a recommendation of certain PT information services by others),

5. Sociodemographics (e.g., gender, age, education, income, Internet access). 
Looking up PT information can be classified as a goal-directed behaviour (Perugini and Conner, 2000): people consult information as a means to an end, for example, making a journey successfully or performing activities at the destination (e.g., meeting friends, attending a business meeting). Attitude theory states that intention (e.g., the intention to consult PT information) is a direct determinant of behaviour and that intention in turn is determined by (Ajzen, 1991):

- $\quad$ attitudes (e.g., the degree to which one has a favourable or unfavourable evaluation of using public transport or consulting PT information);

- $\quad$ perceived behavioural control (e.g., the perceived ease or difficulty of consulting PT information); and

- $\quad$ subjective norms (e.g., the perceived encouragement by important others, such as family and friends, to consult PT information).

Accordingly, we explore in this paper the effect of travel attitudes, information factors, and social surrounding on the actual use of pre-trip PT information (rather than on the intention to use PT information). Also, we study travel behaviour since it captures the amount of past experience with various travel modes and can be seen as a proxy for habit (Verplanken et al., 1997). Just like the other researched factors, sociodemographics could form a constraint (or a facilitator) for consulting PT information (Farag and Lyons, 2010). However, sociodemographics could be poor proxies for the underlying behavioural and attitudinal characteristics of individuals which may determine travel information use (Chorus et al., 2006a). Therefore, Figure 1 shows that we do not expect a direct effect of sociodemographics on PT information use, but an indirect effect via travel behaviour, travel attitudes, and information factors. Given the results of our previous research (Farag and Lyons, 2008, 2010), we expect all the other 
factors described above to have both direct and indirect effects on PT information use (see Figure 1).

Additionally, we also researched what affects information factors (e.g., the dislike to look up train information) and social surrounding (e.g., receiving a recommendation of certain PT information services by others). Based on previous findings (Farag and Lyons, 2008), Figure 1 shows that we expect travel behaviour, travel attitudes, and sociodemographics to affect information factors. However, we did not develop any hypotheses regarding what factors affect social surrounding, hence, Figure 1 does not show any factors affecting social surrounding. We explored these relationships during the analysis process.

We expect the following relationships to occur between the various factors (see Figure 1). Social surrounding might affect individuals' travel behaviour, since many people do not reach their travel decisions entirely alone, but operate in a social context and are influenced by the behaviour and opinions of other people around them (Farag and Lyons, 2010). Moreover, travel attitudes will probably influence individuals' actual travel behaviour. Of course, a continuous interaction between these two factors (in which they simultaneously affect each other) is very likely to exist. For simplicity reasons, we have only depicted oneway arrows in Figure 1. However, two-way relationships have also been studied (e.g., how travel attitudes and travel behaviour affect each other simultaneously), as well as 'reverse' relationships (e.g., the effect of PT information use on travel behaviour). Thus, we tested our hypothetical model in an explorative way. 


\section{Research design and methodology}

\subsection{Data employed}

A travel information survey was designed and piloted among fifty people. The main topics covered were: personal travel behaviour, public transport information awareness and use, attitudes towards travel and PT information use, and sociodemographics. The questionnaire took approximately twenty minutes to fill out. A random sample of 10,000 households in Bristol $(5,000)$ and Greater Manchester $(5,000)$ in the UK was then selected via the municipalities' population administration and received the postal survey at the beginning of December 2007. A post card reminder was sent two weeks later. Only one person aged 18 or over could participate per household. The overall response rate was $13 \%(n=1327)$. The questionnaire could also be filled out online by those receiving an invitation to participate, but only $6 \%$ of the total response sample did so. We have administered our survey only in the English language, since most PT information in the UK that we are aware of is offered only in English. However, this means our study excludes linguistic minorities. Future research could fill this gap by collecting data on language ability.

Two different cities were researched to potentially capture different experiences with and attitudes towards public transport and PT information use. Compared to Bristol (population 410,500 (Bristol City Council, 2008)), Manchester (population 442,100 (Manchester City Council, 2008)) has a more extensive public transport system including a tram service and a light rail system. Also, bus use is cheaper (shuttle buses with three different routes operating in the city centre of Manchester are even free to use). Consequently, bus use is higher in Manchester than in Bristol: nearly a quarter (22\%) of Mancunians travel to work by bus, while only $13 \%$ of Bristolians do so (Bristol 
City Council, 2008; Manchester City Council, 2008). The latter drive and walk more often to work than Mancunians.

Nearly two-thirds (65\%) of all respondents are from Bristol, while the rest of the respondents (35\%) are from Manchester. Of all the Manchester respondents, $64 \%$ lives in the city of Manchester, while the rest resides in the surrounding area of Greater Manchester. Thus, the majority of respondents are urban residents. Just over half (54\%) of respondents are under fifty years old. In the total sample, $43 \%$ are employed full time, $16 \%$ part time, and $26 \%$ are retired. One-third of the sample are single, while over a quarter $(28 \%)$ have children. Nearly one-fifth (18\%) of the respondents do not hold a driving licence and nearly a quarter (22\%) do not have access to a car in their household for personal use. Overall, $28 \%$ of British adults do not hold a driving licence (ONS, 2008). More information about the sample and the operationalisation of variables included in the analyses can be found in Table 1.

To give an indication of the representativeness of our sample we compared it with census data for Bristol and Manchester (Bristol City Council, 2008; Manchester City Council, 2008). Our sample is characterised by an overrepresentation (ranging between $5 \%$ and $9 \%$ ) of females, older persons, highly educated persons, and individuals who have access to at least one car in their household. Despite these differences, we believe they do not compromise the study's purpose to better understand how various types of factors are related to pre-trip PT information use. Since we included all these potential biases (gender, age, education, car access) in the SEM analysis, they have been accounted (and controlled) for. Their effect on pre-trip PT information use has been studied while simultaneously studying the effect of other factors on PT information use. Thus, we investigated which factors are dominant in affecting PT information use, while controlling for relevant other factors. 


\subsection{Operationalisation of variables and sample differences}

In the survey, we provided respondents with the following definition of public transport: "In the following questions 'public transport' means: train, coach, bus, tram, underground. It does NOT include taxi or air travel." The precise nature of PT information use was not defined, allowing coverage of various information sources (e.g., timetables, telephone, Internet, asking staff or someone you know) and various types of information (e.g., confirmatory information such as departure times, information about travel modes for journey planning). An empirical investigation of the use of various PT information types and sources can be found elsewhere (Farag and Lyons, 2008).

Respondents answered the following question about their pre-trip PT information use for leisure and business trips: "How often do you consult public transport information before you make the following types of journeys within the UK?". Those respondents who indicated that they never make such journeys were excluded from the analyses. Only respondents holding a driving licence or having access to a car in their household were included in the analysis of pretrip PT information use for comparing travel by car with public transport.

The trip distinctions used here (i.e., leisure and business trips) usually tend to be mutually exclusive, although people could combine business with leisure of course. Moreover, any trip type or category will contain a range of more specific journey contexts - as explored by Mokhtarian et al. (2006) in the case of leisure trips. Nevertheless, the researched trip types are assumed to differ at least to some extent in trip purpose and arrival time-sensitivity.

The answer categories of the question about getting a PT information service recommended by others (see Table 1) were divided into: "yes, please specify the name of the information service(s)" and "yes, but I can't remember the information service(s)". They were collapsed into one category for the analysis. 
Half of the respondents who answered positively, indicated they could not remember the PT information service they had been recommended. We also collapsed the answer categories of the question about comparing car with public transport (see Table 1) into two categories for the analysis.

The sample of respondents who answered the question about using PT information to compare car with public transport $(n=1003)$, contains relatively more persons who are highly educated (47\%) and have a high income (33\%) compared to the whole sample. Also, more respondents in this sample use the Internet daily (65\%) and have Internet access at home (81\%). The other sample used in the analysis of leisure trips closely resembles the main sample reported in Table 1 , but has less respondents $(17 \%)$ who never use the Internet. Respondents who make business trips $(n=429)$ differ as follows from the overall sample (whose percentages are given in brackets):

- $53 \%$ are female $(58 \%)$,

- average age is 42 years old, standard deviation is 11 years (mean=49, $s d=16)$

- $64 \%$ are highly educated $(41 \%)$,

- $47 \%$ have a high income $(27 \%)$,

- $85 \%$ use the Internet daily (56\%),

- $89 \%$ have Internet access at home (73\%),

- $94 \%$ hold a driving licence $(82 \%)$,

- $12 \%$ do not have access to a car in their household (22\%).

Furthermore, respondents who make business trips travel more often by car in general ( $83 \%$ at least weekly) and train (29\% at least monthly) compared to the overall sample. 
As Figure 1 shows, we used several indicators to measure each type of factor (see, for example, travel attitudes). Figure 2 (see section 4) clarifies which indicators were studied and found to be statistically significant.

\subsection{Method of analysis}

We chose SEM as our method of analysis because of the assumed interdependencies between the various factors studied and to better understand directions of influence. In SEM, a variable can be both dependent (that is, an outcome variable) and independent (that is, an explanatory variable) at the same time. Moreover, SEM distinguishes between direct, indirect, and total effects (Jöreskog and Sörbom, 2001). A total effect consists of one direct and one or more indirect effects. An SEM analysis consists of two parts: a measurement model and a structural model. In the measurement model, latent variables are explained by their indicators (observed variables). In the structural model, relationships between the latent variables can be modelled. The structural model captures the regression effects of exogenous (independent) variables on endogenous (dependent) variables, and the regression effects of endogenous variables on each other.

Covariance analysis was used to estimate the coefficients in an SEM model. A model covariance matrix was fitted on a sample covariance matrix, while iteratively minimizing the differences between the model-implied and observed values. Maximum likelihood estimation was used as the method of estimation. In addition to a covariance matrix, an asymptotic covariance matrix was calculated as input for the analysis. In this way, standard errors and chi-squares were corrected for non-normality (Jöreskog, 2005). A disadvantage of constructing an asymptotic covariance matrix is that a listwise deletion procedure is applied, which resulted in many missing cases (18\%). Therefore, we imputed values for 
missing items using the technique of Expectation Maximization (EM), which substitutes values for missing data through a maximum likelihood estimation procedure (Olinsky et al., 2003). Non-recursive structural equation models with latent variables were estimated using LISREL software version 8.72 (Jöreskog and Sörbom, 2001). A measurement model for travel attitudes and information factors was developed. In the structural model, parameters were estimated for the relationships between the endogenous and exogenous variables, and among the endogenous variables. The measurement model and the structural model were estimated simultaneously.

There are several goodness-of-fit measures that can be used to assess the outcome of an SEM analysis. Frequently-used measures include (Golob, 2003): the root mean square error of approximation (RMSEA), which is based on chisquare values and measures the discrepancy between observed and predicted values per degree of freedom (a good model has an RMSEA value of less than 0.05); and goodness-of-fit measures, which compare the sample and modelimplied variance-covariance matrices, such as the standardized root mean square residual (SRMR) (a value less than 0.05 is considered a good fit). Another goodness of fit measure is the Satorra-Bentler chi-square, which takes non-normality into account by using an asymptotic covariance matrix (Jöreskog, 2005). Squared multiple correlations $\left(R^{2}\right)$ give insight into the proportion of explained variance of the dependent variables included in the model.

It has to be noted that a direct comparison of goodness-of-fit indicators between the models for different trip types is very difficult due to the varying sizes of the covariance matrices that are estimated (the sizes of these matrices differ because diverse samples are considered in each model). This means that it is difficult to assess which model explains PT information use best. Standardized coefficients are given in Table 2 (see section 4) to enable comparisons of the magnitude of the effects. 


\section{Results}

\subsection{Measurement model}

The measurement model specifies how latent variables are indicated by the observed variables, describing the reliabilities and validities of those observed variables. Standardized parameter estimates of the observed indicators for the latent variables show that the measurement model performs reasonably well. The parameter values for car attitude are 0.636 and 0.901 ; for bus attitude 0.677 and 0.973 ; for public transport attitude 0.644 and 0.799 ; and for the ease of consulting PT information online the parameter values range between 0.776 and 0.936. The exact question wording of these variables can be found in Table 1 .

\subsection{Business and leisure trips}

Respondents consult PT information relatively more often before making a business trip than before making a leisure trip. More than half $(57 \%)$ of the respondents who make business trips said they consult PT information very often or always, whereas only $42 \%$ of the respondents indicated this before making a leisure trip (see Table 1). However, regardless of trip type, a relatively large proportion of the respondents state that they never obtain PT information before making this trip: $28 \%$ in the case of leisure trips and $20 \%$ for business trips.

Reliability analysis using Cronbachs' alpha showed that most respondents gave very similar answers regarding their PT information use for leisure and business trips (Cronbachs' alpha=0.805). If respondents indicated they use PT information before making a business trip, they often also indicated they use PT information before making a leisure trip. This high degree of consistency might 
indicate that pre-trip PT information use is more strongly related to characteristics of the person (such as travel habits), rather than characteristics of the trip. Moreover, as Table 2 shows, the use of PT information before going on a leisure or business trip is most strongly affected by the same set of factors, namely travel behaviour and sociodemographics. These are factors that pertain to a person rather than a trip. The indices of overall model fit show that the models for business and leisure trips perform well (respectively, RMSEA $=0.000$ and RMSEA=0.017). Figure 2 graphically represents the final outcomes of the SEM analysis.

The usual mode for making leisure and business trips has the strongest direct effect on pre-trip PT information use. Respondents who usually travel by car consult less often PT information. This finding is consistent with earlier research showing how habit can limit the chance that an alternative transport choice is considered (Kenyon and Lyons, 2003; Verplanken et al., 1997). Additionally, people might know or think that public transport is not a viable option for most of their trips and, therefore, refrain from consulting PT information. Respondents who frequently travel by train or coach look up more often PT information before making a leisure trip compared to respondents who infrequently use public transport.

Investigation of the direction of influence between public transport use and PT information use revealed that a two-way interaction exists. However, overall, the best results were obtained by modelling public transport use as affecting PT information use. It seems that because respondents use public transport frequently, they consult PT information more often compared to respondents who use public transport infrequently or never. Similarly, Goulias et al. (2004) found that public transport use increases awareness and use of online travel information. PT information use may reinforce public transport decisions rather than bring them about (Ipsos MORI, 2006). 
Contrary to our expectations, direct effects of sociodemographics on PT information use were found, rather than indirect effects via travel behaviour, travel attitudes, and information factors. Highly educated persons consult more often PT information before making a leisure trip, as do females, and persons with Internet access at home. Frequent Internet users and females consult more often PT information before making a business trip. Even after controlling for frequency of public transport use in the analysis, an effect of education and gender is found on PT information use. Possibly, some important factors have been overlooked that might explain why there still is a direct effect of sociodemographics on pre-trip PT information use. For example, highly educated persons might be more interested and skilled in obtaining and using any kind of information in general compared to less educated persons. Perhaps, the gender effect is related to different travel patterns between men and women due to employment status, household structure, child care, and maintenance tasks (Nobis and Lenz, 2005). For example, women tend to make more, but shorter trips than men (Nobis and Lenz, 2005). Also, women tend to chain their trips more often than men do (McGuckin and Nakamoto, 2005).

Furthermore, the results show that frequent internet users and people who have easy access to internet (namely, at their homes) are more likely to use PT information for various trip types compared to others. This illustrates the importance of the availability of PT information online, since for many people the Internet is their main source for obtaining PT information (Farag and Lyons, 2008). Only age has, as supposed, an indirect effect on pre-trip PT information use for leisure trips. However, the total effect is statistically insignificant. Younger persons dislike to consult train information, but compared to older persons, they receive a recommendation to use a particular PT information service more often. These two contrasting effects lead to a near zero total effect of age on PT information use. 
In the case of business trips, the effect of social surrounding on PT information use is stronger than the effect of information factors (see Table 2). Respondents who state that they do not know many people who use public transport regularly consult less often PT information before making a business trip. Also, respondents who dislike looking up train information use less often PT information before making a business trip. No statistically significant effect was found from travel attitudes on PT information use for business trips. However, in the case of leisure trips, travel attitudes have a stronger effect on PT information use than information factors and social surrounding. Respondents with a positive car attitude consult less often PT information before making a leisure trip, as do respondents who dislike looking up train information and respondents who never received a recommendation from others to use a particular PT information service.

\subsection{Information factors and social surrounding}

Below, we discuss for business and leisure trips what affects information factors (the dislike to look up train information) and social surrounding (receiving a recommendation to use a certain $\mathrm{PT}$ information service by others; not knowing many people who use public transport regularly). The dislike to look up train information is affected by infrequent rail travel for both business and leisure trips. Respondents who hardly or never travel by train dislike looking up train information. This might imply a learning effect: the more often one travels by public transport, the more proficient one gets in consulting PT information. Similar results have been found in previous research (Derek Halden Consultancy, 2006). We did not find evidence for the reverse (because people dislike consulting train information they travel less by train), which supports earlier research concerning bus travel (Cain, 2007). 
For leisure trips, the strongest effect on the dislike to consult train information comes from other information factors: respondents having difficulties consulting PT information online dislike looking up train information, which results in less frequent PT information use compared to others. For business trips, social surrounding has the strongest effect on the dislike to consult train information: respondents who indicate that they do not know many people who use public transport regularly state more often than others that they dislike looking up train information. Again, this might suggest that consulting PT information is a learning process in which social surrounding could be helpful. Additionally, Cain (2007) found that public transport users have more often previous experience with consulting PT information compared to non-users of public transport, which might make it easier for the former to understand PT information.

Thus, the dislike to consult train information is affected by information factors, social surrounding, and travel behaviour. We also found that younger respondents dislike consulting train information compared to older respondents. However, as mentioned before, the net total effect of age on PT information use is statistically insignificant, because younger persons have also received a recommendation to use a particular PT information service more often than older persons.

Additionally, respondents who received a recommendation to use a particular PT information service use public transport more frequently and have a more positive attitude towards bus travel than those who did not receive such a recommendation. This seems to suggest that one has to be receptive to such recommendations both in terms of travel behaviour (i.e. use public transport) and travel attitudes. Perhaps, people who need PT information (because they travel more frequently by public transport) remember that they received a recommendation more often compared to others. Alternatively, they might actively have sought a recommendation about PT information services from 
people they know. Social surrounding and travel behaviour mutually affect each other, but the effect of travel behaviour on social surrounding is stronger than the other way round.

Finally, respondents who say they do not know many people who use public transport regularly are frequent car users, rarely or never travel by train, and tend to live in Bristol. The latter finding matches the lower usage of buses in Bristol compared to Manchester. However, Bristolians do not consult PT information less often than Mancunians, since the total effect of city on PT information use is not statistically significant (see Table 2). This might be partly explained by our focus on long distance trips, where train (and coach) use is far more likely to occur than bus or tram use.

\subsection{Consulting PT information to compare car with public transport}

We also asked respondents how often they consult PT information with the intention to compare car with public transport for unfamiliar or long distance (=over 50 miles) journeys. Nearly half $(43 \%)$ of the respondents said they never compared car with public transport (see Table 1). Indices of model fit show that the model performs well (RMSEA $=0.004)$ (see Table 2). Travel behaviour and travel attitudes are the factors that most strongly affect whether people compare car with public transport for unfamiliar or long distance trips.

The results illustrate that respondents who never use PT information to compare travel modes (as opposed to those who at least sometimes do so) tend to have a negative public transport attitude, infrequently or never travel by train, tend to be less educated, and male. Public transport attitude consists of two statements (see Table 1), one of which measures the willingness to travel by public transport if parking was difficult or expensive. Our finding that people are more willing to compare travel modes when parking is difficult is in line with 
research that expects parking restraint to have a major influence on mode choice (Derek Halden Consultancy, 2006).

Moreover, respondents who never use PT information to compare travel modes have never received a recommendation to use a particular PT information service by others and are infrequent car users. The latter finding could appear to be surprising. However, infrequent car users might have less opportunity to compare travel modes, since they travel infrequently by car to start with. Respondents on a high income use PT information less often to compare between car and public transport than those on lower incomes. This finding suggests that reducing travel costs might be a reason for comparing travel modes.

The effects of car and train use on comparing travel modes are stronger than the other way round. This implies that there might be relatively little effect of PT information use on travel behaviour. To investigate this further, we asked respondents who indicated that they at least sometimes compare travel modes $(\mathrm{N}=549)$, how often they had decided to travel by public transport instead of by car after consulting PT information. The majority (78\%) said they had done so sometimes, while $15 \%$ said they had done this often. Respondents were also asked how often they had decided to travel by car instead of by public transport after having consulted PT information. Half of the respondents said they had done this sometimes, while $48 \%$ said they had done this often. These figures suggest that it happens more often that people decide to travel by car after comparing travel modes than by public transport.

Furthermore, respondents who already have decided to travel by public transport when they consult PT information are more likely to be people who, unsurprisingly, stated that they never compare travel modes and who have a positive public transport attitude. Despite having no statistically significant effect, we included the ease of consulting online PT information in the model, because 
leaving it out considerably deteriorated the overall model fit. Any total effects of other factors via this variable on PT information use are also statistically insignificant (see Table 2). Respondents who find it difficult to consult PT information online often do not have Internet access at home, are relatively older, and less educated. Moreover, respondents who are less aware of PT telephone and web information services also have more difficulties consulting PT information online. This seems to imply that the more PT information services one knows, the easier it is to consult PT information online. Increasing the awareness of PT information services might, therefore, be of some benefit in facilitating their use.

\subsection{Summary}

Regardless of trip type, the factors most strongly related to pre-trip PT information (non-)use are travel behaviour and sociodemographics. Respondents who usually travel by car when making a business or leisure trip consult less often PT information compared to people who habitually do not make these type of trips by car. Moreover, males consult less often PT information before making a business or leisure trip compared to females. Additionally, males compare car less often with public transport for unfamiliar or any long distance trips, just as infrequent train users do and respondents with a negative attitude towards public transport. Social surrounding affects pre-trip PT information use: respondents who state that they do not know many people who use public transport regularly or that they never received a recommendation by others to use a particular PT information service, consult less often PT information than others. Finally, respondents who dislike looking up train information and who find it difficult to consult PT information online, also use PT information less often compared to other respondents. 


\section{Conclusions}

Despite the investment in and growing availability of public transport (PT) information sources, levels of PT information use reported in the UK may be assumed to be failing to meet the aspirations if not the expectations of some providers (GfK NOP, 2007). This quantitative study has sought to understand if, and how, travel behaviour, travel attitudes, information factors, social surrounding, and sociodemographics are associated with pre-trip PT information use and non-use. Long distance leisure and business trips within the UK have been examined, as well as PT information use to compare car with public transport and its consequences for mode choice. Additionally, we studied what factors affect information factors and social surrounding.

The results show that all factors mentioned above directly (and indirectly) affect PT information use (see Figure 2). Travel behaviour and sociodemographics have the strongest effect on pre-trip PT information use for both business and leisure trips. Furthermore, travel behaviour and travel attitudes have the strongest effect on using PT information to compare car with public transport. This suggests that PT information use could be more about the person' than the specific trip. We found that public transport use affects PT information use more strongly than vice versa. Also, respondents tend to travel more often by car than by public transport after comparing travel modes. Both information factors and social surrounding have the strongest effect on the dislike to look up train information. Finally, travel behaviour and travel attitudes most strongly affect whether or not respondents indicate they received a recommendation from others to use a particular PT information service.

Together, these findings have several implications. First, they suggest that if public transport use is successfully encouraged, this might lead to an increase in PT information use. Public transport providers and PT information service 
providers face the challenge to influence people's attitudes towards using public transport and to correct any misconceptions persons might have (e.g., a false belief about the number of changes of a particular train journey, while a direct link exists). Such misconceptions could deter the use of both public transport and PT information. As long as public transport is not a viable option (and sometimes rightly so) in people's mind, chances are slim that they will use public transport or consult any PT information. Improved availability of PT information and awareness of it may not of itself result in greater consideration of public transport. However, PT information is very likely to be consulted when people are considering public transport use. Therefore, marketing efforts by PT information service providers should simultaneously aim to promote public transport use and awareness of PT information availability. Moreover, access to PT information could in certain circumstances increase the use of public transport. Persons who occasionally use public transport might extend this use to more trips once they have gained familiarity with both the public transport system and consulting PT information. Also, if PT information services would be advertised on trains and buses, public transport users might be reminded to use these information services and consequently might travel again by public transport.

Second, the results illustrate the utmost importance of providing PT information in such a way that it is easy to obtain and understand. This especially holds for online PT information, since the Internet is for many people the main source of any information they like to seek. Respondents who dislike looking up train information and who find it difficult to consult online travel information use PT information less often than others. PT information service providers should be aware of this barrier to PT information use and ensure that the information they provide is easy accessible and understandable. Our results show that such an endeavour could be rewarded in the form of word-of-mouth 
recommendations of particular PT information services by individuals to each other. Respondents who were recommended to use certain PT information services by people they know state more often than others that they consult PT information. Thus, such recommendations (received from someone you know and trust) have a direct positive effect on PT information use, which illustrates the powerful potential of word-of-mouth. Furthermore, we found that an increased awareness of PT information services positively affects the ease of consulting PT information online. Knowing specific PT information services apparently facilitates the online search for PT information. This implies that PT information service providers could benefit from periodically monitoring the public's awareness of the availability of their services, provided they respond adequately to the monitoring results (e.g., by efforts to raise awareness).

Third, the findings show that travel behaviour and social surrounding interact with each other. For example, respondents who said they received a recommendation to use a particular PT information service, travel frequently by public transport and have a positive attitude towards it. Also, respondents who state they dislike looking up train information, often do not know many people who use public transport regularly, travel infrequently by train, and find it difficult to consult online PT information. These examples show that social surrounding could facilitate PT information use (e.g., by providing an informal learning environment) as well as constrain it. Accordingly, public transport providers and PT information service providers could tailor their marketing efforts by exploring social marketing techniques which aim to alter attitudes and behaviour by investigating and evaluating consumers' needs. Such an approach could be suitable if it explicitly takes individuals' travel behaviour, travel attitudes, and social surrounding into account. Providing people with good experiences of using public transport (e.g., via free travel tickets) and of using PT information (e.g., via staff at stations explaining how to use PT information websites) could 
ultimately pay itself back in an increased use of both public transport and PT information.

While hitherto it may have been assumed by policymakers that greater use of PT information was a key to influencing travel choices, the reality is rather more refined. Even though our expectations of the effect of PT information use on public transport use should be modest, this does not mean that PT information is unimportant. Awareness of and information about public transport options is still a necessary precursor for any potential use of public transport. Therefore, a more concerted effort is needed of both public transport providers and PT information service providers to successfully address people's travel needs and to influence their willingness to use public transport.

\section{References}

AEA Technology, 2007. Transport Direct evaluation: final report. UK Department for Transport. Available from:

<http://www.dft.gov.uk/162259/245385/249577/TD_Final_Report_Version_1.21. pdf> (cited 05.09.08).

Ajzen, I., 1991. The theory of planned behavior. Organizational Behavior and Human Decision Processes 50, 179-211.

Bristol City Council, 2008. Statistics and census information. Available from: <http://www.bristol.gov.uk/ccm/navigation/council-and-democracy/statistics-andcensus information/;jsessionid=9FF6B1FCA642815482F9CF76EAAB7A15> (cited 23.06.08). 
Cain, A., 2007. Are printed transit information materials a significant barrier to transit use? Journal of Public Transportation 10, 33-52.

Chorus, G. C., Molin, E. J. E., Van Wee, B., 2006a. Use and effects of Advanced Traveller Information Services (ATIS): a review of the literature. Transport Reviews 26, 127-149.

Chorus, G. C., Molin, E. J. E., Van Wee, B., Arentze, T. A., Timmermans, H. J. P., 2006b. Responses to transit information among car-drivers: regret-based models and simulations. Transportation Planning and Technology 29, 249-271.

Chorus, G. C., Arentze, T. A., Timmermans, H. J. P, Molin, E. J. E., Van Wee, B., 2007. Travelers' need for information in traffic and transit: results from a web survey. Journal of Intelligent Transportation Systems 11, 57-67.

Derek Halden Consultancy, 2006. Barriers to modal shift. Scottish Executive Transport Research Planning Group. Available from: <http://www.scotland.gov.uk/Publications/2003/09/18178/26386> $>\quad$ (cited 02.07.08).

Farag, S., Lyons, G., 2008. What affects use of pretrip public transport information? Empirical results of a qualitative study. Transportation Research Record 2096, 85-92.

Farag, S., Lyons, G., 2010. Explaining public transport information use when a car is available: attitude theory empirically investigated. Transportation 37, 897913. 
GfK NOP, 2007. Travel Information Services Wave $10-8^{\text {th }}$ to $13^{\text {th }}$ March 2007. UK Department for Transport. Available from:

< http://www.dft.gov.uk/173086/249736/249739/wave10 > (cited 05.09.08).

Golob, T. F., 2003. Structural equation modeling for travel behaviour research. Transportation Research part B: Methodological 37, 1-25.

Goulias, K. G., Kim, T., Pribyl, O., 2004. A longitudinal analysis of awareness and use for advanced traveler information systems. Paper presented at the 83rd Annual Meeting of the Transportation Research Board, Washington, D.C, USA, January 2004.

Grotenhuis, J., Wiegmans, B. W., Rietveld, P., 2007. The desired quality of integrated multimodal travel information in public transport: customer needs for time and effort savings. Transport Policy 14, 27-38.

Ipsos MORI, 2006. Contribution made by Traveline Scotland to modal shift. Scottish Executive Social Research. Available from: <http://www.scotland.gov.uk/Resource/Doc/139659/0034503.pdf> (cited 06.06.08).

Jöreskog, K. G., Sörbom, D., 2001. LISREL 8: user's reference guide. Scientific Software International, Lincolnwood.

Jöreskog, K. G., 2005. Structural equation modeling with ordinal variables using LISREL. Available from: <http://www.ssicentral.com/lisrel/techdocs/ordinal.pdf> (cited 07.07.08). 
Kenyon, S., Lyons, G., 2003. The value of integrated multimodal traveller information and its potential contribution to modal change. Transportation Research part F: Traffic Psychology and Behaviour 6, 1-21.

Lyons, G., Avineri, E., Farag, S., Harman, R., 2007. Strategic review of travel information. UK Department for Transport. Available from: <http://www.dft.gov.uk/162259/245385/249577/Strategic_Review_of_Travel_1.p $d f>$ (cited 02.07.08).

Manchester City Council. Statistics and census information. Available from: <http://www.manchester.gov.uk/site/scripts/documents.php?categorylD=200088 $>$ (cited 23.06.08).

McGuckin, N., Nakamoto, Y., 2005. Differences in trip chaining by men and women. In: Research on Women's Issues in Transportation, Volume 2: Technical Papers, Conference Proceedings 35, Transportation Research Board, Washington D.C. Available from:

http://onlinepubs.trb.org/onlinepubs/conf/CP35v2.pdf (cited 27.10.10).

Mokhtarian, P. L., Salomon, I., Handy, S. L., 2006. The impacts of ICT on leisure activities and travel: a conceptual exploration. Transportation 33, 263-289.

Molin, E. J. E., Timmermans, H. J. P., 2006. Traveler expectations and willingness to pay for Web-enabled public transport information services. Transportation Research part C: Emerging Technologies 14, 57-67.

Nobis, C., Lenz, B., 2005. Gender differences in travel patterns: role of employment status and household structure. In: Research on Women's Issues 
in Transportation, Volume 2: Technical Papers, Conference Proceedings 35, Transportation Research Board, Washington D.C. Available from: http://onlinepubs.trb.org/onlinepubs/conf/CP35v2.pdf (cited 27.10.10).

Olinsky, A., Chen, S., Harlow, L., 2003. The comparative efficacy of imputation methods for missing data in structural equation modeling. European Journal of Operational Research 151, 53-79.

Office for National Statistics (ONS), 2008. Travel and tourism. Driving licences. UK Department for Transport. Available from: <http://www.statistics.gov.uk/CCl/nugget.asp?ID=1093\&Pos=2\&ColRank=2\&Ra $\mathrm{nk}=672>($ cited 01.07.08).

Peirce, S., Lappin, J., 2004. Why don't more people use advanced traveler information? Evidence from the Seattle area. Paper presented at the 83rd Annual Meeting of the Transportation Research Board, Washington, D.C, USA, January 2004.

Perugini, M., Conner, M., 2000. Predicting and understanding behavioral volitions: the interplay between goals and behaviors. European Journal of Social Psychology 30, 705-731.

Van der Horst, R., 2006. Getting there \& away. The role of travel information in recreational day trips, with a specific focus on the mode and destination choice. Utrecht University, Utrecht, the Netherlands. Available from: <http://igitur-archive.library.uu.nl/dissertations/2006-1121-201558/index.htm> (cited 17.06.08). 
Verplanken, B., Aarts, H., Van Knippenberg, A., 1997. Habit, information acquisition, and the process of making travel mode choices. European Journal of Social Psychology 27, 539-560. 
Table 1 Frequency distribution and definition of variables

Variables
Pre-trip public transport information use
How often do you consult public transport information before
you make the following types of journeys within the UK?

you make the following types of journeys within the UK?

A leisure trip of over 50 miles within the UK

$1=$ Always

116230

$2=$ Very often

$\begin{array}{ll}2=\text { Very often } & 12 \\ 3=\text { Quite often } & 9\end{array}$

$4=$ Sometimes $\quad 20$

A business trip of over 50 miles within the UK

5 = Never

$2=$ Very often

28

=

$4=$ Sometimes

$5=$ Never

How often do you obtain public transport information to compare car with

$0=$ Compa

$1=$ Never compares car with public transport

$\% \quad$ Mean

SD

public transport for unfamiliar or long distance (=over 50 miles) journeys?

\section{Travel behaviour}

How often do you normally travel using the following types of transport?

Car or van (as driver)

$0=$ Less often or never

$1=$ At least once a week

$1=$ At least once a month

$2=$ At least once every 3 months

$3=$ At least once a year

$4=$ Less often or never

$1=$ At least once every 3 months

$2=$ At least once a year

$3=$ Less often or never

$1=$ Mostly by car

2 = Sometimes by car, sometimes by public transport

$3=$ Mostly by public transport

$1=$ Mostly by car

2 = Sometimes by car, sometimes by public transport

$3=$ Mostly by public transport

A leisure trip of over 50 miles within the UK

A business trip of over 50 miles within the UK 


\section{Travel attitudes}

I like travelling by car (either as driver or passenger)

My experience of travelling by car (either as driver or passenger) is good

I like travelling by local bus

My experience of travelling by local bus is good If I am travelling to an unfamiliar destination, I will consider going by $1=$ Strongly disagree, $7=$ Strongly agree public transport

If I think that it might be difficult or expensive to park at my destination, I $1=$ Strongly disagree, $7=$ Strongly agree will consider going by public transport

\section{Information factors}

Have you heard of any of the following websites or phone services for Continuous

public transport information? (National Rail Enquiries, Traveline, National Minimum = 0, Maximum = 8

Express, Trainline, Transport Direct, Transport for London)

Even if you might never use it, how easy would you / do you find it to obtain public transport information via a website before you travel?

Even if you might never use it, how easy would you / do you find it to understand a website for public transport information?

Even if you might never use it, how much would you / do you trust a $0=$ Not at all, $10=$ Very much

website for public transport information?

I dislike looking up train information

When I look up public transport information I have already decided to use $1=$ Strongly disagree, $7=$ Strongly agree public transport

\section{Social surrounding}

Have other people (for example, colleagues, family, or friends) ever $0=$ No

recommended the use of a particular PT information service to you?

I do not know many people who use public transport regularly
$1=$ Strongly disagree, 7 = Strongly agree $1=$ Strongly disagree, $7=$ Strongly agree $1=$ Strongly disagree, $7=$ Strongly agree $1=$ Strongly disagree, 7 = Strongly agree

$1=$ Strongly disagree, 7 = Strongly agree

1284

1262

1238

1207 
Table 1 Continued (2)

\begin{tabular}{|c|c|c|c|c|c|}
\hline Variables & & $\mathbf{N}$ & $\%$ & Mean & SD \\
\hline \multicolumn{6}{|l|}{ Sociodemographics } \\
\hline Gender & $\begin{array}{l}0=\text { Male } \\
1=\text { Female }\end{array}$ & 1291 & $\begin{array}{l}42 \\
58\end{array}$ & & \\
\hline Age & Continuous, Minimum = 18, Maximum = 95 & 1278 & & 48.96 & 16.79 \\
\hline Education & $\begin{array}{l}1=\text { Low (no qualifications, O-level, GCSE-grade) } \\
2=\text { Medium (A-level, vocational training) } \\
3=\text { High (academic degree) }\end{array}$ & 1263 & $\begin{array}{l}32 \\
27 \\
41\end{array}$ & & \\
\hline Income (=monthly net household income) & $\begin{array}{l}1=\text { Low }(1970 \text { or less US dollars }) \\
2=\text { Medium }(1970-5908 \text { US dollars }) \\
3=\text { High }(5908 \text { or more US dollars })\end{array}$ & 1095 & $\begin{array}{l}26 \\
47 \\
27\end{array}$ & & \\
\hline Frequency Internet use for work and/or personal reasons & $\begin{array}{l}1=\text { Daily Internet use } \\
2=\text { Weekly Internet use } \\
3=\text { Monthly Internet use or less often } \\
4=\text { Never uses Internet }\end{array}$ & 1301 & $\begin{array}{l}56 \\
17 \\
6 \\
21\end{array}$ & & \\
\hline Internet access at home & $\begin{array}{l}0=\text { Yes } \\
1=\text { No }\end{array}$ & 1300 & $\begin{array}{l}73 \\
27\end{array}$ & & \\
\hline City & $\begin{array}{l}0=\text { Bristol } \\
1=\text { Manchester }\end{array}$ & 1323 & $\begin{array}{l}65 \\
35 \\
\end{array}$ & & \\
\hline
\end{tabular}


Table 2 Standardized coefficients of direct and total ${ }^{1}$ effects for leisure and business trips and for comparing car with public transport (significance at least $p<0.05$, unless indicated otherwise ${ }^{2}$ )

\begin{tabular}{|c|c|c|c|c|c|c|c|c|c|}
\hline & & $\begin{array}{l}\text { URE TR } \\
\mathrm{N}=1136 \text { ) }\end{array}$ & & & $\begin{array}{l}\text { INESS T } \\
(\mathrm{N}=429)\end{array}$ & & & $\begin{array}{l}\text { MPARE } \\
\text { H PT (N) }\end{array}$ & $\begin{array}{l}\text { ARR } \\
\text { 1003) }\end{array}$ \\
\hline Structural model & $\mathrm{Ou}$ & me varia & & Ou & ome vari & les & & come var & bles \\
\hline Explanatory variables & PT info ${ }^{3}$ & Dislike & Recom & PT info & Dislike & Know & PT info & Online & Decided $^{4}$ \\
\hline Information factors & & & & & & & & & \\
\hline PT info: Never consults PT info & & & & & & & & & 0.279 \\
\hline to compare car with PT & & & & & & & & & 0.279 \\
\hline Dislike: Dislike looking up train & 0.076 & & & 0.088 & & & & & \\
\hline information & 0.076 & & & 0.088 & & & & & \\
\hline Online: Easy to consult PT & & -0.284 & & & & & $-0.051^{b}$ & & \\
\hline information online & $-0.022^{a}$ & -0.284 & & & & & $-0.051^{b}$ & & $-0.014^{b}$ \\
\hline Awareness of PT info services & & & & & & & $-0.007^{b}$ & $\begin{array}{l}0.135 \\
0.135\end{array}$ & $-0.002^{b}$ \\
\hline Social surrounding & & & & & & & & & \\
\hline Recom: Got a recommendation to & -0.071 & & & & & & -0.171 & & \\
\hline use a particular PT info service & -0.071 & & & & & & -0.171 & & -0.048 \\
\hline Know: I do not know many & & & & 0.148 & 0.218 & & & & \\
\hline people who use PT regularly & & & & 0.167 & 0.218 & & & & \\
\hline Travel behaviour & & & & & & & & & \\
\hline Public transport is the usual mode & -0.478 & & & -0.524 & & & & & \\
\hline for making this type of trip & -0.478 & & & -0.524 & & & & & \\
\hline Train use (infrequent or never) & $0.054^{\mathrm{a}}$ & 0.243 & -0.131 & & 0.176 & 0.194 & 0.275 & & \\
\hline & 0.082 & 0.243 & -0.131 & 0.048 & 0.218 & 0.194 & 0.275 & & 0.077 \\
\hline Coach use (infrequent or never) & 0.096 & & $-0.106^{\mathrm{a}}$ & & & & & & \\
\hline & 0.104 & & $-0.106^{a}$ & & & & & & \\
\hline Car use (weekly) & & & & & & 0.275 & -0.158 & & \\
\hline & & & & 0.046 & 0.060 & 0.275 & -0.158 & & -0.044 \\
\hline Travel attitudes & & & & & & & & & \\
\hline Positive car attitude & $\begin{array}{l}0.121^{a} \\
0.121^{a}\end{array}$ & & & & & & & & \\
\hline Positive bus attitude & $-0.007^{a}$ & & $\begin{array}{l}0.099 \\
0.099\end{array}$ & & & & & & \\
\hline Positive public transport attitude & & & & & & & $\begin{array}{l}-0.254 \\
-0.254\end{array}$ & & $\begin{array}{l}0.270 \\
0.199\end{array}$ \\
\hline Sociodemographics & & & & & & & & & \\
\hline Female & $\begin{array}{l}-0.136 \\
-0.136\end{array}$ & & & $\begin{array}{l}-0.164 \\
-0.164\end{array}$ & & & $\begin{array}{l}-0.071 \\
-0.071\end{array}$ & & -0.020 \\
\hline Age & & -0.142 & -0.142 & & & & & -0.174 & \\
\hline & $-0.001^{b}$ & -0.142 & -0.142 & & & & $0.009^{b}$ & -0.174 & $0.002^{b}$ \\
\hline High education & -0.177 & & & & & & -0.216 & $-0.071^{\mathrm{a}}$ & \\
\hline & -0.177 & & & & & & -0.220 & $-0.071^{a}$ & -0.061 \\
\hline High income & & & & & & & 0.128 & & \\
\hline & & & & & & & 0.128 & & 0.036 \\
\hline Infrequent Internet user / non-user & & & & 0.229 & & & & & \\
\hline & & & & 0.229 & & & & & \\
\hline No Internet access at home & 0.093 & & & & & & & -0.541 & \\
\hline & 0.093 & & & & & & $0.028^{b}$ & -0.541 & $0.008^{b}$ \\
\hline Manchester resident & & & & & & -0.165 & & & \\
\hline & & & & $-0.027^{b}$ & $-0.036^{b}$ & -0.165 & & & \\
\hline${ }^{1}$ Total effects are in italic, ${ }^{2 a}$ & $=$ significant & $<0.10,{ }^{b}=\mathrm{n}$ & significant & & & & & & \\
\hline${ }^{3} \mathrm{PT}$ info $=$ Frequency of con & sulting pre-tri & informatio & $1=$ always, 5 & never) & & & & & \\
\hline${ }^{4}$ Decided $=$ When I look up & T informatio & ave already & cided to $\mathrm{u}$ & & & & & & \\
\hline
\end{tabular}


Table 2 Continued

\begin{tabular}{|c|c|c|c|c|c|c|c|c|c|}
\hline \multirow{3}{*}{ Structural model } & \multicolumn{3}{|c|}{$\begin{array}{l}\text { LEISURE TRIPS } \\
(\mathrm{N}=1136)\end{array}$} & \multicolumn{3}{|c|}{$\begin{array}{l}\text { BUSINESS TRIPS } \\
(\mathrm{N}=429)\end{array}$} & \multicolumn{3}{|c|}{$\begin{array}{l}\text { COMPARE CAR } \\
\text { WITH PT }(\mathrm{N}=1003)\end{array}$} \\
\hline & \multicolumn{3}{|c|}{ Outcome variables } & \multicolumn{3}{|c|}{ Outcome variables } & \multicolumn{3}{|c|}{ Outcome variables } \\
\hline & PT info & Dislike & Recom & PT info & Dislike & Know & PT info & Online & Decided \\
\hline \multicolumn{10}{|l|}{ Goodness of fit indicators } \\
\hline $\mathrm{R}^{2}$ (reduced form) & 0.476 & 0.141 & 0.078 & 0.531 & 0.184 & 0.061 & 0.395 & 0.034 & 0.511 \\
\hline Degrees of freedom & \multirow{2}{*}{\multicolumn{3}{|c|}{$\begin{array}{l}68 \\
91.288(p=0.031)\end{array}$}} & \multicolumn{3}{|c|}{14} & \multicolumn{3}{|l|}{56} \\
\hline Satorra-Bentler $\chi^{2}$ ( $p$-value) & & & $91.288(p=0.031)$ & \multicolumn{3}{|c|}{$12.074(p=0.600)$} & \multicolumn{3}{|c|}{$56.934(p=0.440)$} \\
\hline SRMR & \multicolumn{3}{|c|}{0.026} & \multicolumn{3}{|c|}{0.034} & \multicolumn{3}{|c|}{0.025} \\
\hline RMSEA & \multicolumn{3}{|l|}{0.017} & \multicolumn{3}{|l|}{0.000} & \multicolumn{3}{|l|}{0.004} \\
\hline$p$-value for RMSEA $<0.05$ & \multicolumn{3}{|l|}{0.356} & \multicolumn{3}{|l|}{0.350} & \multicolumn{3}{|l|}{0.436} \\
\hline
\end{tabular}


Figure 1 Hypothetical model explaining pre-trip public transport information use and information factors (researched variables are in italics) 
Travel attitudes

- Car attitude

- Train attitude

- Bus attitude

- Willingness to travel by PT

- Preference for car when travelling with friends

- Dislike of way finding by car in unfamiliar area
Sociodemographics

- Gender

- Age

- Household type

- Presence of children

- Education

- Full time employment

- Income

- City

- Car access

- Internet use

- Internet access
Information factors

- Awareness of PT info services

- Ease of obtaining PT info via phone, web, and leaflet

- Ease of understanding PT info via phone, web, and leaflet

- Amount of trust in PT info via phone, web, and leaflet

- Dislike of looking up train info

- Dislike of looking up bus info

- When consulting PT info, already decided to use PT

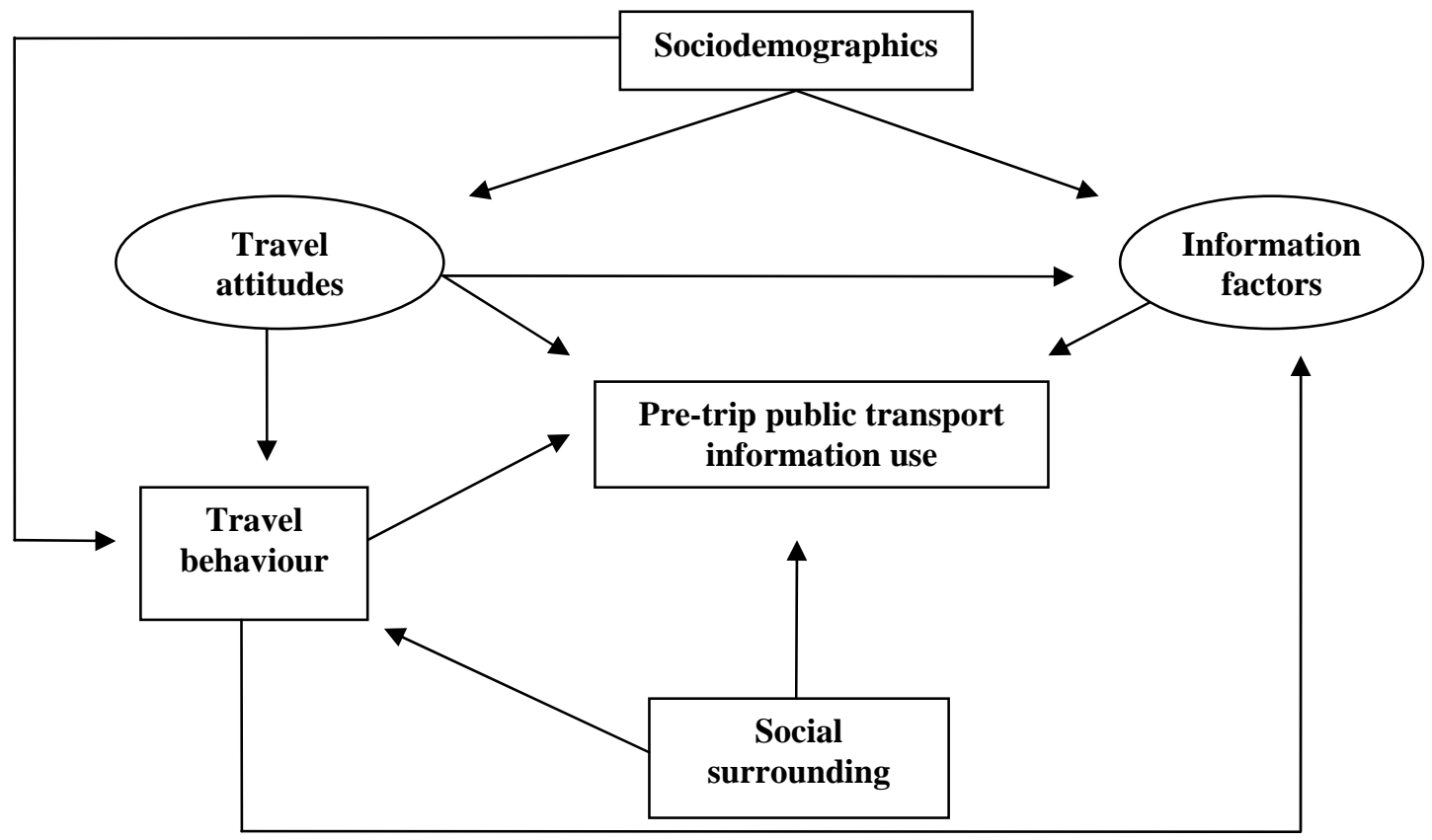

Travel behaviour

- Car use

- Train use

- Coach use

- Bus use

- Frequency of making a leisure/business trip

- Usual mode of transport when making a leisure/business trip
Social surrounding

- Recommended to use a PT info service by others

- Discouraged to use a PT info service by others

- Most friends use PT regularly

- Don't know many people who use PT regularly 
Figure 2 Results of Structural Equation Modelling (SEM) analysis (statistically significant variables are in bold) 
Travel attitudes

- Car attitude

- Train attitude

- Bus attitude

- Willingness to travel by PT

- Preference for car when travelling with friends

- Dislike of way finding by car in unfamiliar area
Sociodemographics

- Gender

- Age

- Household type

- Presence of children

- Education

- Full time employment

- Income

- City

- Car access

- Internet use

- Internet access
Information factors

- Awareness of PT info services

- Ease of obtaining PT info via web

- Ease of understanding PT info via web

- Amount of trust in PT info via web

- Dislike of looking up train info

- Dislike of looking up bus info

- When consulting PT info, already decided to use PT

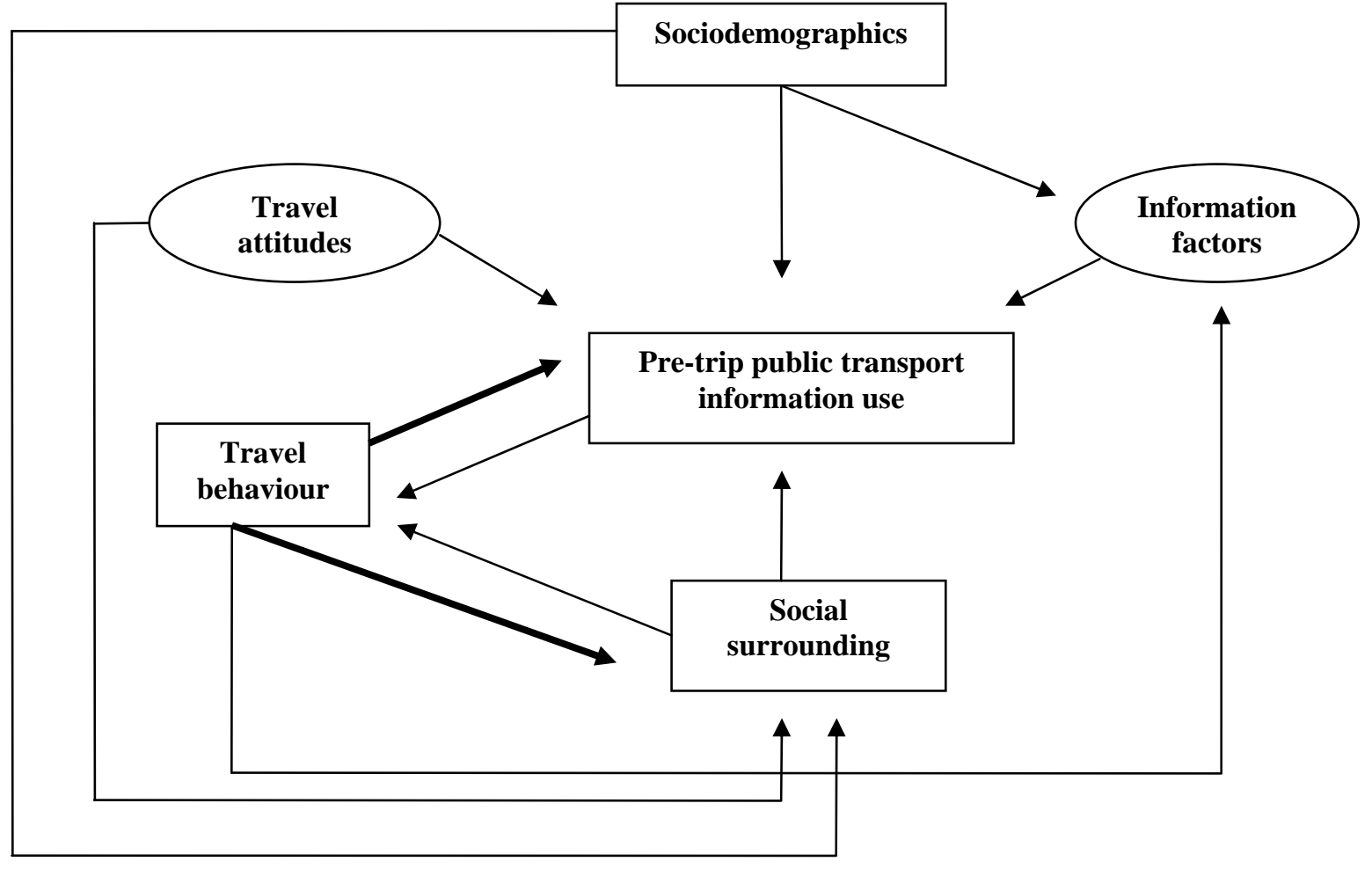

Travel behaviour

- Car use

Social surrounding

- Train use

- Recommended to use a PT info service by others

- Coach use

- Discouraged to use a PT info service by others

- Frequency of making a leisure/business trip

- Usual mode of transport when making a leisure/business trip

- Most friends use PT regularly

- Don't know many people who use PT regularly 